\title{
Determinants of childhood diarrhea among under-five year old children in Nigeria: A population-based study using the 2013 demographic and health survey data
}

\author{
Anselm S. Berde ${ }^{1}$, Sıddıka Songül Yalçın², Hilal Özcebe ${ }^{3}$, Sarp Üner ${ }^{4}$, Özge Karadağ-Caman ${ }^{4}$ \\ ${ }^{1}$ Africa Unit for Transdisciplinary Health Research, North-West University (Potchefstroom Campus), South Africa; ${ }^{2}$ Division \\ of Social Pediatrics, Department of Pediatrics ${ }^{3}$ Department of Public Health, Hacettepe University Faculty of Medicine; \\ ${ }^{4}$ Institute of Public Health, Hacettepe University, Ankara, Turkey. E-mail: get2anselm@gmail.com \\ Received: 6th September 2017, Revised: 30th October 2017, Accepted: 17th December 2017
}

SUMMARY: Berde AS, Yalçın SS, Özcebe H, Üner S, Karadağ-Caman Ö. Determinants of childhood diarrhea among under-five year old children in Nigeria: A population-based study using the 2013 demographic and health survey data. Turk J Pediatr 2018; 60: 353-360.

The study aims to identify socioeconomic, demographic, environmental and child baseline factors associated with Childhood Diarrhea (CD) among underfive year old children in Nigeria. We utilized cross-sectional data from the 2013 Nigerian Demographic and Health Survey (NDHS). The study covered 18,047 mother-baby pairs. The key outcome variable was $\mathrm{CD}$. Chi-square tests and binary logistic regression were used to test for association between CD and related factors. The prevalence of $\mathrm{CD}$ was $12.6 \%$. In the multivariate analysis, the following factors were significantly associated with increased risk of CD; younger mother's age, household size of seven and above, unsafe disposal of child's last fecal matter and younger child's age. Also, children living in all geopolitical zones as compared to the South South geopolitical zone had significantly higher risk of $\mathrm{CD}$. Interventions such as information, education and communication programs on hygiene and sanitation aimed at reducing $C D$ in Nigeria should focus more on groups at risk for CD highlighted in our study.

Key words: childhood diarrhea, Nigeria, mothers, children, under-five.

Diarrhea leads to the loss of 525,000 children under five each year and is the second leading cause of death in children of this age group. ${ }^{1}$ In Sub Saharan Africa (SSA), diarrhea is a major cause of morbidity and mortality among children aged less than five years old.2-3 Also, nutritional deficits caused by diarrhea affect children's fitness, cognition, growth and performance at school.4-5

The higher prevalence of Childhood Diarrhea (CD) recorded in developing countries like Nigeria could be attributed to lack of safe drinking water, sanitation, and hygiene, as well as the overall poorer health and nutritional status of children. ${ }^{6}$ Nigeria is among the top 15 countries with the highest number of diarrhea deaths in children under 5 and as of 2015 , approximately 77,000 under 5 year old
Nigerian children died as a result of diarrhea diseases. ${ }^{7} \mathrm{CD}$ is recognized as a significant public health problem in the country.

The World Health Organisation (WHO) and the United Nations Children's Fund (UNICEF) recognise diarrhea and pneumonia as the two major preventable causes of child death and have launched the integrated "Global Action Plan for the Prevention and Control of Pneumonia and Diarrhea (GAPPD)" with a goal of ending preventable child deaths from pneumonia or diarrhea by 2025.8 To achieve this goal, a focused, coordinated, flexible and integrated national action on diarrhea control by all countries is needed.

Previous studies have shown that the determinants of $\mathrm{CD}$ are multi-factorial in nature 
and involve socioeconomic, demographic, child baseline factors and environmental conditions. ${ }^{2}$, 9-11 In Nigeria, identifying children at greatest risk of diarrhea will help in planning national action on diarrhea control, thus, helping to achieve the GAPPD goal of ending child deaths through diarrhea by 2025 in Nigeria.

This study purpose was to identify key factors associated with CD and to update on previous knowlegde with regards to CD in Nigeria.

\section{Material and Methods}

\section{Sample}

The study utilized data from the 2013 Nigeria Demographic and Health Survey (NDHS), which is the fifth in the series of Demographic and Health Surveys conducted so far in Nigeria. The survey used as sampling frame the list of enumeration areas (EAs) prepared for the 2006 Population Census Nigeria. The sample was selected using a stratified three-stage cluster design consisting of 904 clusters; 372 in urban areas and 532 in rural areas. In the interviewed households, a total of 39,902 women aged 15-49 years were identified as eligible for individual interviews, and 98 percent of them were successfully interviewed. Further details of the sampling techniques and data collection method can be found in the country's DHS manual. ${ }^{12}$ Analysis for this study was restricted to (1) dejure residents (2) singleton births (3) last-born children (4) under five years of age, (5) alive and (6) living with mother. The total sample size was 18,047 . After accounting for sample weights, this corresponded to a sample size of 18,376 .

\section{Dependent Variable}

Our outcome variable "CD" was defined as having diarrhea in the last two weeks preceeding the survey and was expressed as a dichotomous variable with "category 1" for having diarrhea in the last two weeks preceeding the survey and "category 0" for otherwise.

\section{Independent Variables}

The explanatory factors were grouped into socioeconomic and demographic factors, child baseline factors and environmental conditions.

(i) Socioeconomic and demographic variables: Mother's age was recoded into "15-19", "20-24", "25-29", "30-34" and " $\geq 35$ " years. Mother's education was categorized as "no education", "primary", and "secondary and above". Type of place of residence was categorized as urban or rural. Household size was recoded into "six or less" and "seven and above" persons. Number of children under five years in the household was categorized into "two or less" and "three and above". DHS wealth index was categorized as "poorest", "poorer", "middle", "richer" and "richest". The index was constructed using household asset data via a principal components analysis. In terms of region, all the six regions in the country were considered.

(ii) Child baseline variables: Sex of child was grouped into "male" and "female". Age of child was categorized into "five or less", "6-11", "1223", "24-35", "36-47", and "48-59" months.

(iii) Environmental conditions: Source of drinking water was categorized into "improved" and "non-improved source". Toilet facilities were classified into "improved not-shared", "improved-shared," and "non-improved" (Supplementary data). Disposal of the child's last faecal matter was classified into "safe" and "not safe" (Supplementary data).

\section{Statistical Analysis}

Factors associated with CD were analysed using Chi-square tests. Rate of diarrhea and distribution by different independent variables were reported as weighted percentages and then further assessed by binary logistic regression. Bivariate analyses were done with the chisquare tests and variables significant at the 0.25 level were included in the multivariate analysis. The multivariate analysis accounted for the sample design and sample weight using Statistical Package for Social Sciences (SPSS version 21) complex sample analysis method.

\section{Ethics}

The study was approved by the Ethics Committee of ICF International at Calverton, MD, USA and by the Nigeria National Health Research Ethics Committee. Informed consent was obtained from study participants prior to participation in the survey. Permission to use and analyze the data set was obtained by registering the study on the Demographic and Health Survey (DHS) website.

\section{Results}

Characteristics of the sample 
Table I. Sample Characteristics, Nigeria, DHS 2013.

\begin{tabular}{|c|c|c|}
\hline & $\mathrm{N \dagger}$ & $\% \dagger$ \\
\hline \multicolumn{3}{|l|}{ Mother's age (years) } \\
\hline $15-19$ & 1101 & 6.1 \\
\hline $20-24$ & 3496 & 19.4 \\
\hline $25-29$ & 4768 & 26.4 \\
\hline $30-34$ & 3795 & 21.0 \\
\hline$>=35$ & 4887 & 27.1 \\
\hline \multicolumn{3}{|l|}{ Mother's education } \\
\hline No education & 8232 & 45.6 \\
\hline Primary & 3648 & 20.2 \\
\hline Secondary and above & 6167 & 34.2 \\
\hline \multicolumn{3}{|c|}{ Type of place of residence } \\
\hline Urban & 6151 & 34.1 \\
\hline Rural & 11896 & 65.9 \\
\hline \multicolumn{3}{|l|}{ Household size } \\
\hline$\leq 6$ persons & 9932 & 55.0 \\
\hline$\geq 7$ persons & 8115 & 45.0 \\
\hline \multicolumn{3}{|c|}{ Number of children under-five in household } \\
\hline$\leq 2$ & 13105 & 72.6 \\
\hline$\geq 3$ & 4942 & 27.4 \\
\hline \multicolumn{3}{|l|}{ Wealth Index } \\
\hline Poorest & 3932 & 21.8 \\
\hline Poorer & 4079 & 22.6 \\
\hline Middle & 3607 & 20.0 \\
\hline Richer & 3385 & 18.8 \\
\hline Richest & 3044 & 16.9 \\
\hline \multicolumn{3}{|l|}{ Region } \\
\hline North Central & 2794 & 15.5 \\
\hline North East & 3597 & 19.9 \\
\hline North West & 5589 & 31.0 \\
\hline South East & 1506 & 8.3 \\
\hline South South & 2164 & 12.0 \\
\hline South West & 2397 & 13.3 \\
\hline \multicolumn{3}{|l|}{ Sex of child } \\
\hline Male & 9117 & 50.5 \\
\hline Female & 8930 & 49.5 \\
\hline \multicolumn{3}{|l|}{ Age of child in months } \\
\hline$\leq 5$ & 2830 & 15.7 \\
\hline $6-11$ & 3121 & 17.3 \\
\hline $12-23$ & 5371 & 29.8 \\
\hline $24-35$ & 3577 & 19.8 \\
\hline $36-47$ & 1936 & 10.7 \\
\hline $48-59$ & 1212 & 6.7 \\
\hline \multicolumn{3}{|l|}{ Source of drinking water } \\
\hline Improved source & 10153 & 56.4 \\
\hline Non-improved source & 7862 & 43.6 \\
\hline \multicolumn{3}{|l|}{ Toilet Facility } \\
\hline Improved, not shared & 5696 & 31.6 \\
\hline Shared facility & 3225 & 17.9 \\
\hline Non-improved & 9083 & 50.4 \\
\hline \multicolumn{3}{|c|}{ Disposal of the child's last faecal matter } \\
\hline Safe & 10142 & 58.2 \\
\hline Unsafe & 7281 & 41.8 \\
\hline
\end{tabular}

$\dagger$ Unweighted. 
Table II. Rates of Childhood Diarrhea Among Children Under Five Years of Age in Nigeria - Nigeria, DHS 2013.

\begin{tabular}{|c|c|c|c|}
\hline \multirow[b]{2}{*}{ Characteristics } & \multicolumn{2}{|c|}{ Had diarrhea } & \multirow[b]{2}{*}{$\mathrm{p}$ value } \\
\hline & $\mathrm{n} \dagger$ & $\% \dagger$ & \\
\hline \multicolumn{4}{|l|}{ Mother's age (years) } \\
\hline $15-19$ & 181 & 15.7 & \multirow[t]{5}{*}{$<0.001$} \\
\hline $20-24$ & 527 & 14.6 & \\
\hline $25-29$ & 634 & 13.0 & \\
\hline $30-34$ & 444 & 11.5 & \\
\hline$>=35$ & 523 & 10.7 & \\
\hline \multicolumn{4}{|l|}{ Mother's education } \\
\hline No education & 1251 & 14.2 & \multirow[t]{3}{*}{$<0.001$} \\
\hline Primary & 429 & 12.3 & \\
\hline Secondary and above & 629 & 10.4 & \\
\hline \multicolumn{4}{|c|}{ Type of place of residence } \\
\hline Urban & 760 & 11.5 & \multirow[t]{2}{*}{0.001} \\
\hline Rural & 1549 & 13.2 & \\
\hline \multicolumn{4}{|l|}{ Household size } \\
\hline$\leq 6$ persons & 1186 & 11.5 & \multirow[t]{2}{*}{$<0.001$} \\
\hline$\geq 7$ persons & 1123 & 13.9 & \\
\hline \multicolumn{4}{|c|}{ Number of under-five children in household } \\
\hline$\leq 2$ & 1572 & 11.8 & \multirow[t]{2}{*}{$<0.001$} \\
\hline$\geq 3$ & 736 & 14.7 & \\
\hline \multicolumn{4}{|l|}{ Wealth Index } \\
\hline Poorest & 631 & 14.9 & \multirow[t]{5}{*}{$<0.001$} \\
\hline Poorer & 592 & 14.5 & \\
\hline Middle & 426 & 12.2 & \\
\hline Richer & 363 & 11.0 & \\
\hline Richest & 296 & 9.0 & \\
\hline \multicolumn{4}{|l|}{ Region } \\
\hline North Central & 254 & 9.8 & \multirow[t]{6}{*}{$<0.001$} \\
\hline North East & 793 & 25.5 & \\
\hline North West & 750 & 11.1 & \\
\hline South East & 192 & 12.7 & \\
\hline South South & 102 & 5.9 & \\
\hline South West & 218 & 8.1 & \\
\hline \multicolumn{4}{|l|}{ Sex of child } \\
\hline Male & 1146 & 12.4 & \multirow[t]{2}{*}{0.527} \\
\hline Female & 1163 & 12.7 & \\
\hline \multicolumn{4}{|l|}{ Age of child in months } \\
\hline$\leq 5$ & 160 & 5.7 & $<0.001$ \\
\hline $6-11$ & 515 & 16.4 & \\
\hline $12-23$ & 938 & 17.2 & \\
\hline $24-35$ & 476 & 12.9 & \\
\hline $36-47$ & 167 & 8.3 & \\
\hline $48-59$ & 52 & 4.1 & \\
\hline Source of drinking wa & & & \\
\hline Improved source & 1250 & 11.9 & 0.001 \\
\hline Non-improved source & 1057 & 13.5 & \\
\hline Toilet Facility & & & \\
\hline Improved, not shared & 721 & 12.5 & 0.267 \\
\hline Shared facility & 433 & 11.9 & \\
\hline Non-improved & 1153 & 12.9 & \\
\hline Disposal of the child's & & & \\
\hline Safe & 1325 & 12.1 & 0.025 \\
\hline Unsafe & 896 & 13.2 & \\
\hline
\end{tabular}




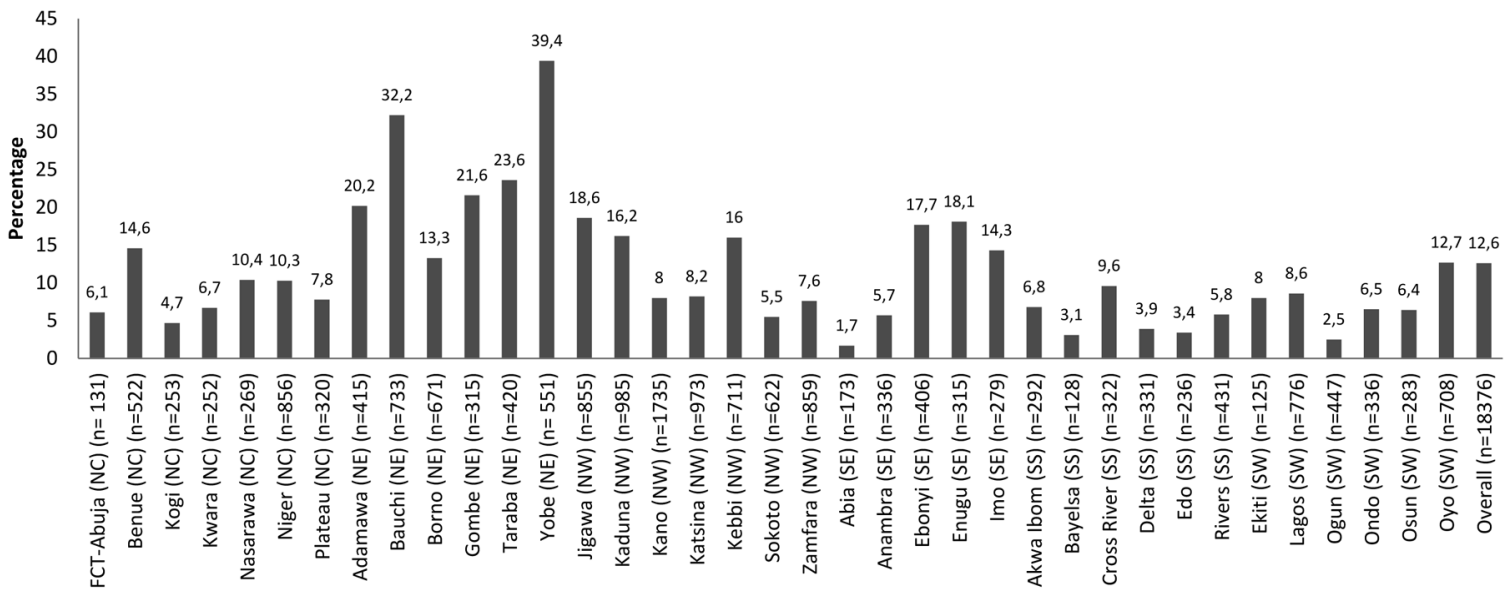

Fig. 1. Prevalence of childhood diarrhea in children under 5 years.

Table III. Risk Factors for Childhood Diarrhea Among Under-Five Children in Nigeria - Nigeria, DHS 2013.

\begin{tabular}{|c|c|c|c|c|c|c|}
\hline \multirow[b]{2}{*}{ Characteristic } & \multicolumn{6}{|c|}{ Childhood Diarrhea } \\
\hline & OR & $95 \% \mathrm{CI}$ & $\mathrm{p}$ value & AOR & $95 \% \mathrm{CI}$ & $\mathrm{p}$ value \\
\hline \multicolumn{7}{|l|}{ Mother's age (years) } \\
\hline $15-19$ & 1.55 & $(1.25-1.92)$ & $<0.001$ & 1.36 & $(1.06-1.75)$ & 0.015 \\
\hline $20-24$ & 1.42 & $(1.22-1.66)$ & $<0.001$ & 1.28 & $(1.07-1.52)$ & 0.006 \\
\hline $25-29$ & 1.25 & $(1.07-1.46)$ & 0.005 & 1.20 & $(1.03-1.41)$ & 0.023 \\
\hline $30-34$ & 1.09 & $(0.93-1.27)$ & 0.289 & 1.07 & $(0.91-1.25)$ & 0.448 \\
\hline$>=35$ & ref & ref & ref & ref & ref & ref \\
\hline \multicolumn{7}{|l|}{ Mother's education } \\
\hline No education & 1.43 & $(1.24-1.65)$ & $<0.001$ & 1.01 & $(0.83-1.23)$ & 0.904 \\
\hline Primary & 1.22 & $(1.04-1.43)$ & 0.016 & 1.09 & $(0.90-1.32)$ & 0.373 \\
\hline Secondary and above & ref & ref & ref & ref & ref & ref \\
\hline \multicolumn{7}{|c|}{ Type of place of residence } \\
\hline Urban & ref & ref & ref & ref & ref & ref \\
\hline Rural & 1.17 & $(1.01-1.36)$ & 0.042 & 0.87 & $(0.73-1.04)$ & 0.128 \\
\hline \multicolumn{7}{|l|}{ Household size } \\
\hline$\leq 6$ persons & ref & ref & ref & ref & ref & ref \\
\hline$\geq 7$ persons & 1.23 & $(1.10-1.38)$ & $<0.001$ & 1.14 & $(1.00-1.31)$ & 0.045 \\
\hline \multicolumn{7}{|c|}{ Number of under-five children in household } \\
\hline$\leq 2$ & ref & ref & ref & ref & ref & ref \\
\hline$\geq 3$ & 1.29 & $(1.16-1.45)$ & $<0.001$ & 1.09 & $(0.95-1.25)$ & 0.225 \\
\hline \multicolumn{7}{|l|}{ Wealth Index } \\
\hline Poorest & 1.77 & $(1.42-2.21)$ & $<0.001$ & 1.09 & $(0.79-1.50)$ & 0.601 \\
\hline Poorer & 1.71 & $(1.40-2.10)$ & $<0.001$ & 1.22 & $(0.91-1.64)$ & 0.189 \\
\hline Middle & 1.40 & $(1.13-1.74)$ & 0.002 & 1.12 & $(0.85-1.48)$ & 0.412 \\
\hline Richer & 1.25 & $(1.01-1.54)$ & 0.037 & 1.08 & $(0.86-1.35)$ & 0.496 \\
\hline Richest & ref & ref & ref & ref & ref & ref \\
\hline \multicolumn{7}{|l|}{ Region } \\
\hline North Central & 1.74 & $(1.26-2.40)$ & 0.001 & 1.64 & $(1.19-2.25)$ & 0.003 \\
\hline North East & 5.51 & $(4.18-7.27)$ & $<0.001$ & 5.76 & $(4.27-7.79)$ & $<0.001$ \\
\hline North West & 2.01 & $(1.53-2.65)$ & $<0.001$ & 2.07 & $(1.50-2.83)$ & $<0.001$ \\
\hline South East & 2.34 & $(1.65-3.31)$ & $<0.001$ & 2.22 & $(1.59-3.10)$ & $<0.001$ \\
\hline South West & 1.43 & $(1.03-1.98)$ & 0.031 & 1.56 & $(1.12-2.17)$ & 0.008 \\
\hline South South & ref & ref & ref & ref & ref & ref \\
\hline \multicolumn{7}{|l|}{ Age of child in months } \\
\hline$\leq 5$ & 1.41 & $(0.95-2.08)$ & 0.085 & 1.27 & $(0.83-1.96)$ & 0.274 \\
\hline $6-11$ & 4.62 & $(3.22-6.63)$ & $<0.001$ & 4.47 & $(2.99-6.67)$ & $<0.001$ \\
\hline $12-23$ & 4.88 & $(3.38-7.05)$ & $<0.001$ & 4.80 & $(3.18-7.26)$ & $<0.001$ \\
\hline $24-35$ & 3.50 & $(2.37-5.15)$ & $<0.001$ & 3.63 & $(2.36-5.57)$ & $<0.001$ \\
\hline $36-47$ & 2.14 & $(1.46-3.14)$ & $<0.001$ & 2.24 & $(1.48-3.41)$ & $<0.001$ \\
\hline $48-59$ & ref & ref & ref & ref & ref & ref \\
\hline \multicolumn{7}{|c|}{ Source of drinking water } \\
\hline Non-improved source & ref & ref & ref & ref & ref & ref \\
\hline Improved source & 0.87 & $(0.74-1.01)$ & 0.061 & 0.99 & $(0.86-1.16)$ & 0.968 \\
\hline \multicolumn{7}{|c|}{ Disposal of the child's last faecal matter } \\
\hline Unsafe & 1.11 & $(0.96-1.28)$ & 0.158 & 1.32 & $(1.13-1.54)$ & $<0.001$ \\
\hline Safe & ref & ref & ref & ref & ref & ref \\
\hline
\end{tabular}

$\mathrm{OR}=$ Odds ratio, $\mathrm{AOR}=$ Adjusted Odds ratio, $\mathrm{CI}=$ Confidence interval, ref: Referance category 
Table I gives the sample characteristics, the highest proportion of mothers $(27.1 \%)$ were in the age group 35 and above years, $45.6 \%$ of mothers had no education, while $65.9 \%$ of mothers lived in rural area. A greater percentage of mothers $(22.6 \%)$ belonged to the poorer wealth quintile and the highest proportion of mothers were from the North West (31.0\%). Male and female children were more or less equal in the sample.

\section{Prevalence of childhood diarrhea}

The overall prevalence of CD in Nigeria was $12.6 \%$. According to states in Nigeria the highest prevalence of $\mathrm{CD}$ was reported in Yobe $(39.4 \%)$, Bauchi $(32.2 \%)$, and Taraba $(23.6 \%)$ while the lowest prevalence of $\mathrm{CD}$ was seen in Abia (1.7\%) Ogun (2.5\%) and Bayelsa (3.1) (Fig. 1).

\section{Bivariate analyses}

CD cases were significantly higher among the following: children whose mothers were in the age group 15-19 years, children whose mothers had no education, rural residence, household size of $\geq 7$ persons, $\geq 3$ number of under-five children in the household, poorest wealth index, North East region, children aged 1223 months, non improved source of drinking water and unsafe disposal of childs last feacal matter (Table II).

\section{Multivariate Analysis}

Results from the multivariate analysis (Table III) indicated that mother's age, household size, region, child's age and disposal of the child's last feacal matter were the determinants of CD.

The following were associated with significantly higher likelihood of CD; younger mothers' age, larger household size, all geopolitical zones as compared to the South South geopolitical zone, younger childs age and unsafe disposal of child's last fecal matter which was associated with a 1.32 times higher odds of having CD as compared to safe disposal of childs last faecal matter.

\section{Discussion}

This study identified key factors associated with CD in Nigeria. The overall prevalence of $\mathrm{CD}$ in the study was $12.6 \%$. The prevalence of $\mathrm{CD}$ showed variability among states in Nigeria, with states like Yobe $(39.4 \%)$ and Bauchi $(32.2 \%)$ recording higher prevalence of $\mathrm{CD}$ and states like Abia (1.7\%) and Ogun (2.5\%) recording lower prevelence. Geopolitical zone was significantly associated with $C D$. The odds of CD were relatively high in all the geopolitical zones as compared to the South South. Regional differences in CD could be attributed to regional differences in educational, industrial and financial development within regions. Parents from regions with higher educational levels and industrial development are likely to have more health-care knowledge which could effectively lower CD associations. ${ }^{13}$

We also found statistically significant associations between $\mathrm{CD}$ and the following variables; mother's age, household size, age of child and disposal method of child's last fecal matter.

In the current study, the odds of CD was higher for children with mothers in the younger age group as compared to mothers, who were 35 years old and above. The study finding was in consonance with what was observed in a previous study done in Nepal; in the study, diarrhea was found to be more common among the children of younger mothers aged $16-25$ years. ${ }^{14} \mathrm{~A}$ possible explanation for the observed association between younger mothers age and increased risk of CD might be explained by the fact that younger mothers lack prior experience in childcare, hygiene and feeding practices. ${ }^{15}$

Household size was also another significant predictor of $\mathrm{CD}$. Children from households with seven or more members had higher likelihood of diarrhea as compared to children from smaller household sizes. This finding is in consonance with another study which was done in Kenya which showed that children belonging to household with big size had higher odds of $\mathrm{CD}$ as compared to children belonging to household with small size. ${ }^{10}$ Our finding with regards to household size and $\mathrm{CD}$ might be explained by the fact that big household size is more likely to be associated with poorer water handling practices, lower hygiene standards due to congestion as well as poorer socio economic status.

Also, this study found the likelihood of diarrhea to be higher among children within the age groups "6-11", "12-23", "24-35", and "36-37" months of age as compared to children, who were in the age range 48-59 months. In the current study, the prevalence of diarrhea peaked 
at 12-23 months and then began to fall at 24-35 and 36-47 month of age. The pattern observed in our study is consistent with that of previous studies done in Ethopia which showed that CD peaked at 12-23 months of age and began to fall after 24 months of age. ${ }^{11}$ The higher risks observed at these ages could be attributed to the fact that children at these ages are either crawling or walking and can easily pick dirt or other contaminated objects for playing or eating. ${ }^{11}$ Furthermore, the period of 6-11 months of age, is when most children start additional food.

Our study findings also revealed that disposal of child's last fecal matter had a strong influence on CD. Unsafe disposal of child's last fecal matter was associated with a higher likelihood of $\mathrm{CD}$ as compared to safe disposal. Our finding is in consonance with previous studies. ${ }^{16-18}$ The finding with regards $\mathrm{CD}$ and unsafe disposal of childs fecal matter may be due to direct fecal contamination of the child's hands or play areas, poor hygiene practices of caregivers or geophagy. ${ }^{19-20}$

Although this study was conducted using a nationally represantative sample data, there are some limitations that must be mentioned. One of the limitation of this study was that the findings were based on cross-sectional data and therefore caution must be exercised in making causal influence of the identified determinants of $\mathrm{CD}$. Also, the study was a secondary analysis of data and some factors that might have effect on diarrhea morbidity were not accounted for.

The finding of factors associated with $\mathrm{CD}$ is of public health significance in Nigeria as CD is a major and preventable cause of death among children under five. For Nigeria to achieve the GAPPD goal of ending preventable child death from diarrhea by 2025, there is a need for public health interventions such as an information, education and communication (IEC) programs on sanitation and hygiene, these interventions should focus more on at risk groups of CD highlighted in our study.

\section{Acknowledgements}

The authors acknowledge Measure DHS for making available the 2013 NDHS data set for this study.

\section{Supplementary data is available at:}

http://www.turkishjournalpediatrics.org/ uploads/turkjped.2018.04.001.S1.pdf

\section{REFERENCES}

1. World Health Organization. Diarrhoeal disease, 2017 Available at: http://www.who.int/mediacentre/ factsheets/fs330/en/ (Accessed October 9, 2018).

2. UNICEF/WHO. Diarrhea: Why Children are Still Dying and What Can be Done. Geneva: UNICEF/WHO, 2009.

3. Bryce J, Boschi-Pinto C, Shibuya K, Black RE. WHO estimates of the causes of death in children. Lancet 2005; 365: 1147-1152

4. Lorntz B, Soares AM, Moore SR, et al. Early childhood diarrhea predicts impaired school performance. Pediatr Infect Dis J 2006; 25: 513-520.

5. Niehaus MD, Moore SR, Patrick PD, et al. Early childhood diarrhea is associated with diminished cognitive function 4 to 7 years later in children in a northeast Brazilian shantytown. Am J Trop Med Hyg 2002; 66: 590-593.

6. Pruss-Ustun A, Bos R, Gore F, Bartram J. Safer water, better health: costs, benefits and sustainability of interventions to protect and promote health. Geneva: World Health Organization, 2008.

7. UNICEF. One is too many: Ending child deaths from pneumonia and diarrhea. New York: UNICEF, 2016

8. WHO/UNICEF. Ending preventable child deaths from pneumonia and diarrhoea by 2025: the integrated global action plan for pneumonia and diarrhoea (GAPPD). Geneva: WHO/UNICEF, 2013.

9. Godana W, Mengistie B. Determinants of acute diarrhoea among children under five years of age in Derashe District, Southern Ethiopia. Rural Remote Health 2013;13: 2329.

10. Mbugua S, Musikoyo E, Ndungi F et al. Determinants of diarrhea among young children under the age of five in Kenya, evidence from KDHS 2008-09. Etude de la population Africaine 2014; 28: 1046-1056.

11. Sinmegn Mihrete T, Asres Alemie G, Shimeka Teferra A. Determinants of childhood diarrhea among underfive children in Benishangul Gumuz Regional State, North West Ethiopia. BMC Pediatrics 2014; 14: 102.

12. National Population Commission (NPC) [Nigeria] and ICF International. 2014. Nigeria Demographic and Health Survey 2013. Abuja, Nigeria, and Rockville, Maryland: NPC and ICF International, 2014.

13. Kandala NB, Ji C, Stallard N, Stranges S, Cappuccio FP Spatial analysis of risk factors for childhood morbidity in Nigeria. Am J Trop Med Hyg 2007; 77: 770-779.

14. Ansari, M, Ibrahim MIM, Shankar PR. Mothers' Knowledge, Attitude and Practice Regarding Diarrhea and its Management in Morang Nepal: An Interventional Study. Trop J Pharm Res 2012; 11: 847-854.

15. El-Gilany AH, Hammad S. Epidemiology of diarrhoeal diseases among children under age 5 years in Dakahlia, Egypt. East Mediterr Health J 2005; 11: 762-775. 
16. Cronin AA, Sebayang SK, Torlesse H, Nandy R. Association of Safe Disposal of Child Feces and Reported Diarrhea in Indonesia: Need for Stronger Focus on a Neglected Risk. Int J Environ Res Public Health 2016; 13: 310.

17. Bawankule R, Singh A, Kumar K, Pedgaonkar S. Disposal of children's stools and its association with childhood diarrhea in India. BMC Public Health. 2017; 17: 12 .
18. Gil A, Lanata C, Kleinau E, Penny M. Children's Feces Disposal Practices in Developing Countries and Interventions to Prevent Diarrheoal Diseases: A Literature Review.Washington, DC: USAID, 2004.

19. Moya J, Bearer CF, Etzel RA. Children's behavior and physiology and how it affects exposure to environmental contaminants. Pediatrics 2004; 113: 996-1006.

20. Majorin F, Freeman MC, Barnard S, Routray P, Boisson $\mathrm{S}$, Clasen T. Child feces disposal practices in rural Orissa: a cross sectional study. PLoS One 2014; e89551. 